\title{
Dynamical Link between Typhoon Activity and the PJ Teleconnection Pattern from Early Summer to Autumn as Revealed by the JRA-25 Reanalysis
}

\author{
Kouhei Yamada $^{1}$ and Ryuichi Kawamura ${ }^{2}$ \\ ${ }^{1}$ Department of Earth Sciences, Faculty of Science, University of Toyama, Toyama, Japan \\ ${ }^{2}$ Section of Earth and Environmental Systems, Graduate School of Science \\ and Engineering for Research, University of Toyama, Toyama, Japan
}

\begin{abstract}
Using the Japanese long-term Re-Analysis project (JRA-25) data, we investigated the seasonal dependence on dynamical links between the Pacific-Japan (PJ) pattern and typhoon activity. It was found that the PJ patterns tend to prevail soon after typhoons to the east of the Philippines migrating northward across the $20^{\circ} \mathrm{N}$ line during the period from July to October. Especially in early summer the low-level southwesterly jet formed by the penetration of the Asian summer monsoon westerlies into the Philippine Sea enables the typhoons to generate the PJ pattern, whereas in autumn the upper-level Asian jet contributes to the appearance of $\mathrm{PJ}$ as an alternative waveguide. The seasonal differences in latitudinal position and strength between the two different waveguides influence the vertical tilt structure of PJ in the vicinity of Japan. It also turns out that even though the typhoons are far away from Japan, they have the potential to indirectly and remotely activate stationary fronts around Japan during the rainy season through the dominance of PJ.
\end{abstract}

\section{Introduction}

The Pacific-Japan (PJ) teleconnection pattern can be identified with a significant summertime extratropical wavetrain emanating out of the vicinity of the Philippine Sea (Nitta 1987; Huang and Li 1987; Kurihara and Tsuyuki 1987). It has been recognized that anomalous convective heating with intraseasonal and interannual time scales stimulates the PJ pattern (e.g., Kawamura et al. 1996; Kosaka and Nakamura 2006). It was not yet clear, however, whether synoptic-scale disturbances, such as tropical cyclones, over the warm pool region of the western North Pacific could also trigger a similar extratropical wavetrain. Fairly recently, Kawamura and Ogasawara (2006) found that one or two typhoons, which are synoptic-scale convective heat sources over the western North Pacific, can induce the barotropic Rossby wavetrain and significantly influence anomalous summer weather in the vicinity of Japan as remote forcing. Their results exhibited a plausible dynamical link between the typhoon activity and the PJ pattern, but their analysis was made only in August. According to Kawamura et al. (1996), the lowlevel southwesterly jet linked with summer monsoon westerlies served as a waveguide of PJ. Such a waveguide disappears in autumn because the summer monsoon westerlies retreat due to land-surface cooling of the Asian continent. If there are no appropriate waveguides, the typhoons may not be able to excite the PJ pattern. On the other hand, the typhoon activity over

Corresponding author: Ryuichi Kawamura, University of Toyama, 3190 Gofuku, Toyama 930-8555, Japan. E-mail: kawamura@sci.u-toyama.ac.jp. @2007, the Meteorological Society of Japan. the western North Pacific is high in autumn as well as summer, and the typhoons are expected to originate and develop in higher latitudes, which might increase the occurrence of extratropical wavetrains due to the typhoons. We may ask how these contradictory conditions modulate the link between the typhoon activity and the PJ pattern. Thus, it would be worthwhile to examine the seasonal relationship between the above two occurrences from early summer to autumn.

Kawamura and Ogasawara (2006) also pointed out that the east-west pressure gradient at low levels between a typhoon and a PJ-induced anomalous anticyclone east of Japan reinforces warm advection and the moisture supply from the lower latitudes, which might trigger heavy rain along the Pacific Ocean side of mainland Japan, even though a typhoon is far away from the mainland. If this is true, the link between the $\mathrm{PJ}$ pattern and the typhoon activity may contribute significantly to activities of the Baiu front in early summer and/or the Akisame front in autumn.

The main objectives of this study are (1) to inspect how the role of typhoons in exciting the PJ pattern in autumn is different from that in summer, and (2) to briefly identify whether the typhoon activity plays an influential role in the stationary rainy band, such as the Baiu front, in the vicinity of Japan as remote forcing.

\section{Data used and analysis procedures}

The datasets used in this study consist of: (1) the Japanese long-term Re-Analysis project (JRA-25) data with a spatial resolution of $2.5^{\circ}$ longitude by $2.5^{\circ}$ latitude for the period of $1979-2001$, and (2) the typhoon track data compiled by the Japan Meteorological Agency (JMA) for the same period. The JMA defines a typhoon as a tropical cyclone with a maximum wind speed exceeding $17.2 \mathrm{~m} \mathrm{~s}^{-1}$ in the vicinity of its center. The forecast model used in the JRA-25 has triangular truncation at wave number 106 (T106) in the horizontal and 40 levels up to $0.4 \mathrm{hPa}$ in the vertical. To supplement in situ observations near tropical cyclones, wind profile data, retrieved using operational tropical cyclone best track data, are adopted in the JRA-25 (Hatsushika et al. 2006). It is thus expected that the representation of tropical cyclones by the JRA-25 is realistic, suggesting that the JRA-25 may be useful in examining the dynamical link between the PJ pattern and the typhoon activity.

According to Wakabayashi and Kawamura (2004), the variability of the PJ is concisely examined, using the $\mathrm{PJ}$ teleconnection index, which is defined as the difference in $850-\mathrm{hPa}$ geopotential height anomalies between the grid points $\left(155^{\circ} \mathrm{E}, 35^{\circ} \mathrm{N}\right)$ and $\left(125^{\circ} \mathrm{E}, 22.5^{\circ} \mathrm{N}\right)$. In order to compute the PJ index for the 1979-2001 period, we used the daily mean geopotential height during the five-month period from June to October, obtained from the JRA-25. First, we excluded the day-to-day fluctuations, applying a low-pass filter (3-day weighted runn- 
Table 1. Number of the extracted PJ events and coexistence frequency of tropical cyclones (typhoons) in each month.

\begin{tabular}{cccc}
\hline Month & PJ events & Coexistence & Frequency $(\%)$ \\
\hline Jun. & 15 & $10(8)$ & $67(53)$ \\
Jul. & 21 & $13(11)$ & $62(52)$ \\
Aug. & 20 & $18(17)$ & $90(85)$ \\
Sep. & 17 & $17(17)$ & $100(100)$ \\
Oct. & 17 & $15(15)$ & $88(88)$ \\
\hline Mean & 18 & $15(14)$ & $81(76)$ \\
\hline
\end{tabular}

ing average) to the daily data, and further omitted the low-frequency components having periods of greater than about one month, using another low-pass filter (31day running average). These filtering procedures are the same as those conducted by Kawamura and Ogasawara (2006). Based on the band-pass-filtered PJ index derived from such a simple combination of the two low-pass filters, we computed its standard deviation $(\sigma)$ and then extracted a period exceeding $+1.5 \sigma$ as a specific event in which the PJ pattern prevails from the north of the Philippines through the central North Pacific. As a result, the number of $\mathrm{PJ}$ events derived during the analyzed period is $15,21,20,17$ and 17 for June, July, August, September and October, respectively (Table 1). We then made composite maps on day -1 , day 0 , day +1 and day +2 for the geopotential height and rainfall anomalies in each month. The "day 0" denotes the peak day of the positive PJ index. These variables are bandpass-filtered values in the same way as the PJ index.

\section{Results}

Table 1 reveals the monthly dependence of the tropical cyclone activity within the western North Pacific region $\left(110^{\circ}-140^{\circ} \mathrm{E}, 10^{\circ}-30^{\circ} \mathrm{N}\right)$ on the extracted PJ events. When PJ patterns reach their peaks (day 0) during the period from June to October, the total number of tropical cyclones (typhoons) located in that region is 73 (68), implying that the coexistence frequency of a tropical cyclone (typhoon) is about $81 \%$ (76\%). In particular, the coexistence frequency of the typhoon reaches $100 \%$ in September. It also turns out that their coexistence frequencies are higher in late summer and autumn than in early summer. Figure 1 shows the mean track of typhoons from day -2 to day +3 in each month on the basis of the results of Table 1 . On day -2 , the mean positions of the typhoons in all months are located to the east of the Philippines. From day -2 to day 0 , the typhoons migrate northward or northwestward and then are concentrated southeast of Taiwan on day 0 when the PJ patterns reach their peaks. After day 0, the typhoons in June, July and August continue to migrate northward or northwestward, but in September and October they change their routes and begin to migrate northeastward. These features suggest that the PJ patterns tend to predominate soon after the typhoons to the east of the Philippines move across the $20^{\circ} \mathrm{N}$ line except in June. It is noteworthy that most of the PJ events are accompanied by the typhoons but the opposite relationship is not true.

As an early summer case, composites of $850-\mathrm{hPa}$ geopotential height anomalies during four days from day -1 to day +2 for June are shown in Fig. 2 along with wave activity fluxes (Takaya and Nakamura 2001) at the same level. The locations of typhoons at 09 LST and climatological westerlies at $850 \mathrm{hPa}$ in June are also exhibited. On day -1 , the typhoons are concentrated in the vicinity of a remarkable negative height anomaly north of the Philippines. An extratropical wavetrain structure

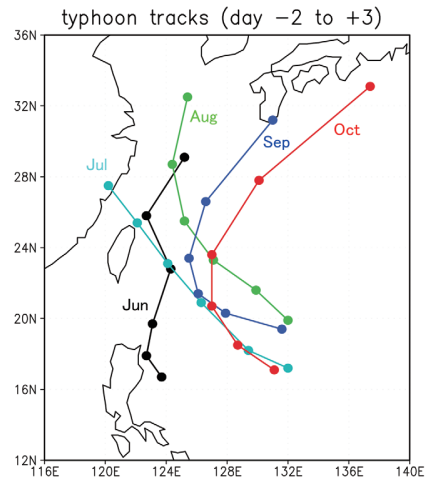

Fig. 1. Mean track of typhoons (including tropical cyclones) in each month. The plot of the tracks is made from day -2 to day +3 .

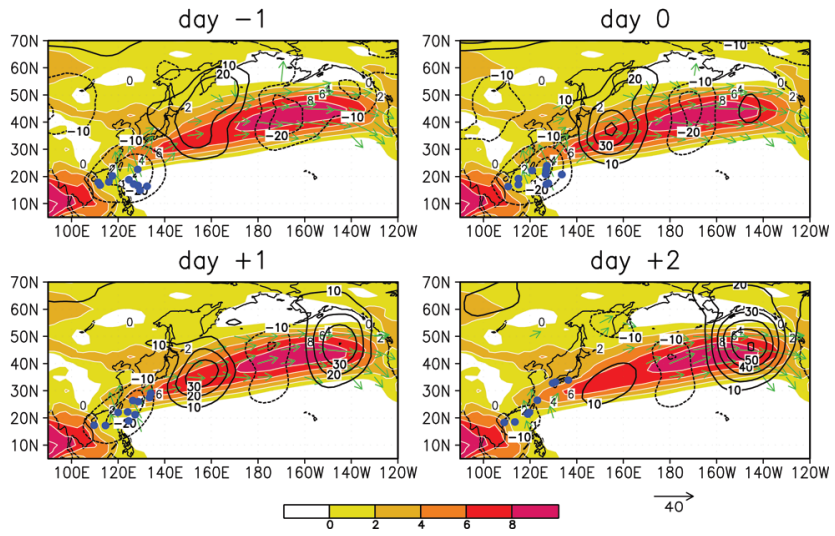

Fig. 2. Composite maps of filtered 850-hPa geopotential height anomalies and wave activity flux from day -1 to day +2 for June. Day 0 denotes the peak phase of the PJ. The location of typhoons at 09 LST (plotted by blue circles) and climatological westerlies at $850 \mathrm{hPa}$ are also shown. The contour interval for height is $10 \mathrm{~m}$. The reference arrow is $40 \mathrm{~m}^{2} \mathrm{~s}^{-2}$. Fluxes of less than $10 \mathrm{~m}^{2} \mathrm{~s}^{-2}$ are suppressed.

associated with the PJ pattern is fully established along the low-level southwesterly jet over the western and central North Pacific from day 0 to day +1 . Northeastward or eastward wave activity fluxes are also evident along the low-level southwesterly jet. As each typhoon migrates northward, the negative height anomaly north of the Philippines decays from day +1 to day +2 , in conjunction with the reduction of the northward wave activity fluxes, whereas a positive height anomaly over the eastern North Pacific amplifies accompanied by distinctive eastward fluxes. The positive anomaly remotely induced by typhoon-related convective heating appears to influence summer weather in Alaska and western Canada. Thus the low-level southwesterly jet linked with the Asian summer monsoon circulations plays a vital role in transporting stationary wave energies eastward as a waveguide, which is consistent with the results of Kawamura et al. (1996). It is interesting to note that Enomoto et al. (2006) also pointed out the importance of the remote effect of a tropical storm on a cut-off cyclone over Europe in boreal summer although they do not focus on the PJ pattern.

As already stated in the introduction, such a waveguide disappears in autumn. Despite its disappearance, however, the number of PJ events in September and October is larger than that in June. Furthermore, the coexistence frequencies of the typhoons in 


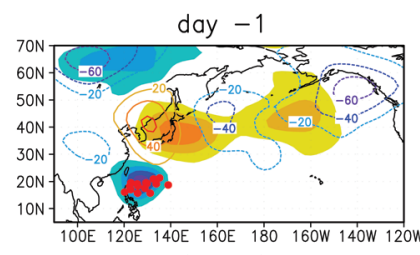

day +1

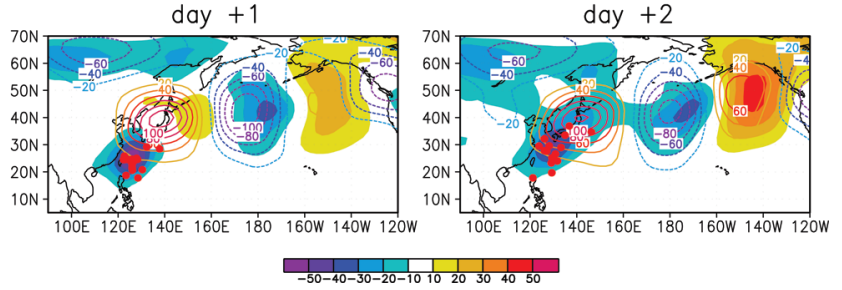

Fig. 3. Composite maps of filtered 200-hPa (color contour) and $850-\mathrm{hPa}$ (color shade) geopotential height anomalies from day -1 to day +2 for October. Day 0 denotes the peak phase of the PJ. The location of typhoons at 09 LST is also plotted by red circles. The color contour and shading intervals are $20 \mathrm{~m}$ and $10 \mathrm{~m}$, respectively.

September and October are also higher than those in June and July, as indicated in Table 1. To inspect this inconsistency, we next present Fig. 3, which reveals composite maps of $850-\mathrm{hPa}$ and $200-\mathrm{hPa}$ geopotential height anomalies from day -1 to day +2 for the October case. Also in October, the PJ pattern is pronounced at the 850$\mathrm{hPa}$ level from day -1 to day +1 . At the $200-\mathrm{hPa}$ level, a salient stationary wavetrain coupled with the low-level PJ pattern is developing from day 0 to day +2 , and a barotropic structure prevails over the central and eastern North Pacific especially on day +2 . Taking a look at the vicinity of Japan, a positive height anomaly at $200 \mathrm{hPa}$ strengthens and reaches its peak on day +1 . This anomaly has a westward-tilt structure with height, in contrast with a poleward-tilt structure seen in summer (Kosaka and Nakamura 2006; Kawamura and Ogasawara 2006). From day +1 to day +2 typhoons approach Japan and, on day +2 , a significant negative height anomaly at the 850 -hPa level covers Japan, while the positive anomaly at the $200-\mathrm{hPa}$ level is still maintained, eventually forming a pronounced baroclinic structure around Japan. As already indicated in Fig. 1, the latitude of the mean position of typhoons on day 0 in October is around $20^{\circ} \mathrm{N}$, which is roughly comparable to that in other months, except for August. It seems, thus, that the extension of typhoon activity toward higher latitudes in autumn does not necessarily facilitate the excitement of the PJ pattern. If so, it is still uncertain why the typhoons can generate the PJ pattern in autumn despite the disappearance of the waveguide in the lower troposphere.

As we know for sure, the main axis of an upper-level subtropical jet from East Asia through the North Pacific gradually shifts equatorward from summer to winter. In particular, the equatorward shift of the upper-level subtropical jet over the Asian continent is already apparent in autumn because of the cooling of the land surface. If the upper-level westerly jet can also serve as an appropriate waveguide, it is most likely that the equatorward shift of the upper-level waveguide facilitates the appearance of the PJ in autumn. Figure 4 demonstrates composites of $200-\mathrm{hPa}$ geopotential height anomalies for October and the associated climatological westerlies at the same level. Wave activity fluxes at $200 \mathrm{hPa}$ are also shown. Indeed, the axis of the upper-level westerly jet over the Asian continent is located around $35^{\circ} \mathrm{N}$, whereas it is positioned north of $40^{\circ} \mathrm{N}$ over the central and eastern North Pacific. In association with the equatorward shift of the westerly jet, the boundary between wetserlies and easterlies at upper levels is located near $20^{\circ} \mathrm{N}$ over the western North Pacific,
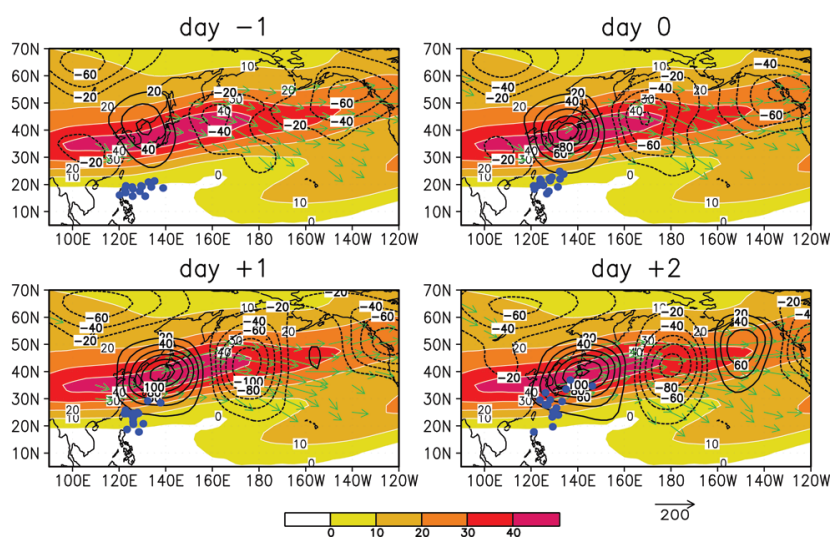

Fig. 4. Composite maps of filtered 200-hPa geopotential height anomalies and wave activity flux from day -1 to day +2 for October. Day 0 denotes the peak phase of the PJ. The location of typhoons at 09 LST (plotted by blue circles) and climatological westerlies at $200 \mathrm{hPa}$ are also shown. The contour interval for height is $20 \mathrm{~m}$. The reference arrow is 200 $\mathrm{m}^{2} \mathrm{~s}^{-2}$. Fluxes of less than $60 \mathrm{~m}^{2} \mathrm{~s}^{-2}$ are suppressed.

corresponding well to the latitude of the mean position of typhoons on day 0 (see Fig. 1 again). When the typhoons migrate northward across the $20^{\circ} \mathrm{N}$ line and penetrate into the upper-level westerly domain from day -1 to day +1 , it turns out that an upper-level positive height anomaly over Japan rapidly amplifies within the westerly jet. Notable eastward wave activity fluxes are observed along the westerly jet from the vicinity of the East China Sea through the North Pacific region; as a consequence, an upper-level stationary Rossby wavetrain is fully established over the North Pacific from day 0 to day +2 . Since the typhoons are accompanied by a strong upward motion and horizontal divergence in the upper troposphere, it is conceivable that the typhoons play an influential role in generating significant vorticity anomalies within the upper-level westerly jet. It is suggested, therefore, that the equatorward shift of the upper-level Asian jet, which serves as an alternative waveguide, enables the typhoons to induce the PJ pattern even in autumn. As stated earlier, the vertical tilt structure of the positive height anomaly around Japan in autumn is considerably different from that in summer. This may be attributed to seasonal differences in latitudinal position and strength between the upper-level Asian jet and the lowlevel southwesterly jet. During early summer, the lowlevel southwesterly jet is, of course, necessary for the excitement of the PJ pattern due to typhoon-induced convective heating, but in autumn, the upper-level Asian jet contributes to the appearance of the PJ as an effective waveguide instead of the low-level jet.

Although effective waveguides of the PJ differ greatly in their detailed characteristics between early summer and autumn, the typhoons can still trigger the PJ pattern. Once the typhoons induce the PJ pattern, an east-west pressure gradient in the lower troposphere strengthens south of Japan, which is expected to increase moisture transport toward Japan. The increase in the moisture supply may affect the activities of stationary fronts around Japan in early summer and autumn. To see how rainfall anomalies are distributed in the vicinity of Japan by a dynamical link between the PJ pattern and typhoon activity, we present Fig. 5 which shows composites of rainfall and $850-\mathrm{hPa}$ geopotential anomalies on the peak day of PJ from June to September. In June and July, positive rainfall anomalies on day 0 are indicated along the Pacific coast of Japan, implying an activation of the Baiu front. As expected, the east-west pressure gradient in the lower troposphere is evidently large at south of Japan. At that 

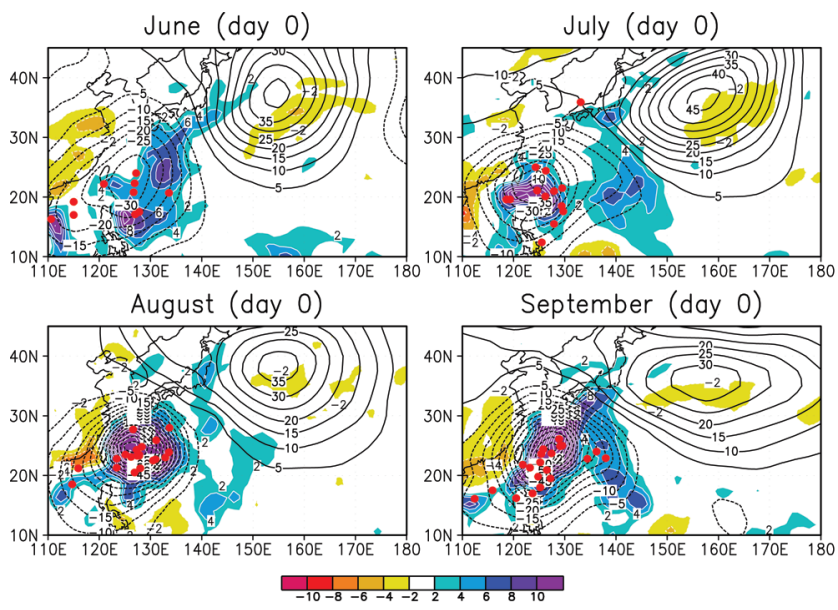

Fig. 5. Composite maps of filtered rainfall (color shade) and 850-hPa geopotential height (contour) anomalies on the peak phase of the PJ in each month. The color shading interval for rainfall is $2 \mathrm{~mm} \mathrm{day}^{-1}$. The contour interval is $5 \mathrm{~m}$. The location of typhoons at 09 LST is also plotted by red circles.

time, most of the typhoons are located far away from Japan and rainfall areas of the typhoons themselves are significantly distinguished from the positive rainfall anomalies along the Pacific coast. A similar rainfall pattern can also be seen in September although it is somewhat obscure in the case of August. The broad features of these changes suggest that even though the typhoons are far away from Japan, they have the potential to indirectly cause heavy rainfall along the Pacific coast of Japan through the excitation of the PJ. In other words, it would be difficult for the typhoons to remotely affect the activation of the stationary fronts in the vicinity of Japan without reinforcement of an anticyclonic circulation east of Japan, which is part of the PJ pattern.

\section{Summary}

In this study, we examined on a daily basis a plausible dynamical link between the typhoon activity and the PJ pattern during the period from early summer to autumn, using composite analyses of geopotential height and rainfall anomalies on the basis of a diagnostic teleconnection index. We highlighted 90 events during which the PJ index exhibited a significant peak value during the period from June to October and found that the tropical cyclone (typhoon) activity is intimately related to 73 (68) of the 90 events, implying that the coexistence frequency of a tropical cyclone (typhoon) is about $81 \%(76 \%)$. This association is valid only for the positive phase of the PJ events and is more evident in late summer and autumn than in early summer.

It was also found that two waveguides, i.e., the lowlevel southwesterly jet and the upper-level Asian jet, are crucial for the excitement of the PJ pattern due to typhoon-induced convective heating during early summer to autumn. The former waveguide that extends from the South China Sea through the central North Pacific is formed by the penetration of the Asian summer monsoon westerlies into the Philippine Sea and contributes to the dominance of PJ especially in early summer. The latter, on the other hand, shifts toward lower latitudes in autumn due to land-surface cooling of the Asian continent, eventually enabling the typhoons to induce the PJ pattern even in autumn instead of the former waveguide. A positive height anomaly around Japan, which is part of the PJ pattern, has a westward- tilt structure with height in autumn, in contrast with a poleward-tilt structure observed in summer. It is suggested that such a difference in the tilt structure arises from seasonal differences in latitudinal position and strength between the above two different waveguides.

A dynamical link between the typhoons and the PJ pattern brings about the activation of stationary fronts in the vicinity of Japan in early summer and autumn because an enhanced east-west pressure gradient in the lower troposphere increases the moisture supply from lower latitudes toward Japan. Even though the typhoons are far away from Japan, they have the potential to indirectly and remotely cause heavy rainfall along the Pacific coast of Japan through the excitation of the PJ.

This study emphasizes the importance of the remote and indirect effect of the typhoon activity on heavy rainfall in and around Japan; further studies are required to quantitatively estimate that effect. Another intriguing issue is how possible changes in typhoon activity related to global warming can modulate the variability of the PJ pattern. It is also possible that such a modulation influences the occurrence of heavy rainfall in the vicinity of Japan. These issues will be reported in the near future.

\section{Acknowledgments}

This research was supported by the research project "R\&D of hydrological modeling and water resources sy stem" of JST/CREST, the research project "Refinement of global and regional water cycle," and Grants-in-Aid (18540432) of the Japanese Ministry of Education, Sports, Culture, Science and Technology.

\section{References}

Enomoto, T., W. Ohfuchi, H. Nakamura and M. A. Shapiro, 2006: Remote effects of tropical storm Cristobal upon a cut-off cyclone over Europe in August 2002. Meteor. Atmos. Phys., in press.

Hatsushika, H., J. Tsutsui, M. Fiorino and K. Onogi, 2006: Impact of wind profile retrievals on the analysis of tropical cyclones in the JRA-25 reanalysis. J. Meteor. Soc. Japan, 84, 891-905.

Huang, R. H., and W. J. Li, 1987: Influence of the heat source anomaly over the western tropical Pacific on the subtropical high over East Asia. Proc. International conference on the general circulation of East Asia, 40-51.

Kawamura, R., T. Murakami and B. Wang, 1996: Tropical and midlatitude 45-day perturbations over the western Pacific during the northern summer. J. Meteor. Soc. Japan, 74, 867890.

Kawamura, R., and T. Ogasawara, 2006: On the role of typhoons in generating PJ teleconnection patterns over the western North Pacific in late summer. Sci. Online Lett. Atmos., 2, 37-40.

Kosaka, Y., and H. Nakamura, 2006: Structure and dynamics of the summertime Pacific-Japan (PJ) teleconnection pattern. Quart. J. Roy. Meteor. Soc., 132, 2009-2030.

Kurihara, K., and T. Tsuyuki, 1987: Development of the barotropic high around Japan and its association with Rossby wave- like propagations over the North Pacific: analysis of August 1984. J. Meteor. Soc. Japan, 65, 237-246,

Nitta, T., 1987: Convective activities in the tropical western Pacific and their impact on the Northern Hemisphere summer circulation. J. Meteor. Soc. Japan, 65, 373-390.

Takaya, K., and H. Nakamura, 2001: A formulation of a phaseindependent wave-activity flux for stationary and migratory quasigeostrophic eddies on a zonally varying basic flow. $J$. Atmos. Sci., 58, 608-627.

Wakabayashi, S., and R. Kawamura, 2004: Extraction of major teleconnection patterns possibly associated with anomalous summer climate in Japan. J. Meteor. Soc. Japan, 82, 15771588.

Manuscript received 5 February 2007, accepted 1 May 2007

SOLA: http://www.jstage.jst.go.jp/browse/sola/ 